\title{
Antibiotic Abuse in Developing Countries
}

\author{
Rizky Abdulah* \\ Division of Pharmacology and Clinical Pharmacy, Faculty of Pharmacy, Universitas Padjadjaran, Indonesia
}

Irrational use of antibiotics has become a common practice in developing countries, where the prevalence of infectious disease burden is aggravated by uncontrolled access to antibiotics. In those countries, antibiotics are prescribed to $44-97 \%$ of patients in hospital, and are often unnecessary [1-4]. In Jakarta Indonesia, doctors prescribed antibiotics to $94 \%$ of young children although they believed the infection was of viral origin [5]. The conditions are worsened with inappropriate self medication of antibiotics. It has been reported that with lack of supervision from healthcare professionals, people in Jordan [6] and Laos [7] consumed non -prescribed antibiotics for treating common cold. This will lead to the increase of microbial resistance, an undesirable effect that causes antibiotic ineffectiveness and not only harmful to the patient but also to the society. The highest antibiotic resistance rate was found in the areas where they are used most [8]. In Pakistan, it has been reported that due to resistance to first line antibiotics, $70 \%$ of hospital acquired neonatal infections that could not be successfully treated by using WHO's recommended regimen [9]. Recent study from Indonesia [10] has reported high rates of resistance of Escherichia coli to ampicillin (73\%), trimethoprimsulphamethoxazole (56\%), chloramphenicol (43\%) and ciprofloxacin (22\%). When antibiotics become ineffective, it will lead to increase of morbidity and premature mortality. Patients infected with antibioticresistant organisms are likely to have higher health expenditure, longer hospital stays and require a second- or third-line drugs treatment that may be less effective, more toxic and more expensive [11,12]. With the limitation in the development of new generations of antibiotics, restrictive and appropriate use of antibiotics is needed to ensure the availability of an effective treatment of microbial infections.

The root causes of the spread of antibiotic resistance are multifactorials and interconnected. It basically caused by inappropriate, irrational, high consumption, and profligate use of antibiotics, combined by a low level of compliance of the patients. The unavailability of a health insurance system that covered most of the citizens in those countries has played a part to the irrational use of antibiotics. For example in Indonesia, almost $86 \%$ of the populations are not covered by any insurance scheme [13], thus, they have to pay in cash everytime they have medical problem. This condition has forced medical doctors to sometimes skip the supporting diagnosis to confirm the bacterial infections, and directly prescribe antibiotics whenever they suspect infections. With the high number of antibiotic prescription, patients believed that antibiotic is a magical medicine that will cure them. From the patients point of view, those with lower income will skip medical consultation and choose for self medication for common diseases, including with non-prescribed antibiotic. They tend to duplicate their previous prescriptions for self medication by making notes of prescribed medicines for future reference if similar medical problems reoccur [14]. Indonesian government has legally included antibiotics to prescription-only medicines whose sale are restricted to hospitals, public health centers, and community pharmacies. However without a strict supervision, antibiotics are easily purchased at a low price without prescription in community pharmacies, drug stores or even in roadside kiosks. Drug stores and kiosks are supposed to be limited to sale only over the counter medicines. As reviewed by Davies and Davies [15] in 2010, commonly used antibiotics are comparatively inexpensive by 10-30 folds in developing countries to those of in the developed countries, although they are not necessarily of the same purity or authenticity. Thus in developing countries, antibiotic use are relatively uncontrolled [15]. Recent study in Yogyakarta, city Indonesia has reported that, in fact, $58 \%$ of the subjects surveyed are intent to do self medication with antibiotics. Furthermore, from subjects that experienced self medication with antibiotics including amoxicillin, ampicillin, fradiomicyn-gramicidin, ciprofloxacin and tetracycline, those antibiotics were used to treat minor diseases such as common cold, cough and fever [14]. A recent study from Mainous et al. [16] have highlighted that currently antibiotics are freely available for purchase on the Internet without a prescription, thus encouraging selfmedication and low quality of care.

With the high market of antibiotics, the substandard products will also play part to the resistency incidence. A substandard antibiotic may cause therapeutic failure due to the lower dosage or absence of the active compounds that finally induce antimicrobial resistance, increase morbidity, mortality and significant economic burden on developing countries [17]. In addition, substandard narrow-spectrum antibiotics may make prescriber think that the antibiotics are not effective, thus unnecessarily prescribe a newer broad-spectrum antibiotics as their first-line treatment for many infections [18]. It has been reported that in Laos, ampicillin contained 3-32\% and tetracycline contained $8-14 \%$ than expected [19], while in Myanmar more than 20 products of antibiotics contain only $13-48 \%$ than expected [20]. Similar problem also has been reported in other developing countries [21,22]. The presence of substandard, or counterfeit, antibiotics is caused by the high prevalence of low income citizens in the developing countries that make the market exist. People with low-income and without any health insurance scheme will purchase medicine, including antibiotics, as cheap as possible. This is accompanied with insufficient regulations and manufacturing control from the authorities [23]. Authorities should optimize a pharmacovigilance program to ensure the drug related problems are detected and resolved. An effective pharmacovigilance, however, is expensive and complicated that make it not a priority for those countries, thus the surveillance and monitoring system became weak or absent. This causes a lack of collaborative global surveillance for antibiotic resistance, thus, inhibiting efforts to identify, characterize, and contain new threats; and to systematically compare and evaluate the value of national resistance containment activities [24].

Antibiotic resistance threatens at all levels of health care and globally challenges public health interventions. There is no single solution to overcome antibiotic resistance problem. Multi aspects approach supported with strong political will from authorities is needed. As the economic condition plays an important role to the irrational use of antibiotics, authorities have to set up a health insurance system

Corresponding author: Rizky Abdulah, Division of Pharmacology and Clinical Pharmacy, Faculty of Pharmacy, Universitas Padjadjaran, Jl. Raya Bandung Sumedang Km 21, Jatinangor 45363, Indonesia, Email: abdulahrizky@gmail.com

Received April 16, 2012; Accepted April 16, 2012; Published April 18, 2012

Citation: Abdulah R (2012) Antibiotic Abuse in Developing Countries. Pharmaceut Reg Affairs 1:e106. doi:10.4172/2167-7689.1000e106

Copyright: ( $) 2012$ Abdulah R. This is an open-access article distributed under the terms of the Creative Commons Attribution License, which permits unrestricted use, distribution, and reproduction in any medium, provided the original author and source are credited. 
to assure the healthcare services to their citizens. This will assure the healthcare professionals to implement the appropriate antibiotic-use policies. Without a health insurance scheme that covers most of the populations, any guidelines and policies regarding the appropriate use of antibiotic will be hard to implement. Furthermore, efforts to educate the patients and community on the danger of antibiotic misuse and overuse, as well as enforcement of existing regulations that will control this potentially vast reservoir of antibiotics must continuously be optimized. The presence of Pharmaceutical Regulatory Affairs, an open access publication will benefit the community in sharing the ideas, experiences, and research's results on the policies regarding the appropriate use of medicines to assure a safe and effective medication.

\section{References}

1. Orrett FA (2001) Antimicrobial prescribing patterns at a rural hospital in Trinidad: evidence for intervention measures. Afr J Med Med Sci 30: 161-164.

2. Ansari F (2001) Use of systemic anti-infective agents in Iran during 1997-1998. Eur J Clin Pharmacol 57: 547-551

3. Chukwuani CM, Onifade M, Sumonu K (2002) Survey of drug use practices and antibiotic prescribing at a general hospital in Nigeria. Pharm World Sci 24 188-195.

4. Arya SC (2004) Antibiotics prescription in hospitalized patients at a Chinese university hospital. J Infect 48: 117-118.

5. Gani L, Arif H, Widjaja SK, Adi R, Prasadja H, et al. (1991) Physician's prescribing practice for treatment of acute diarrhoea in young children in Jakarta. J Diarrhoeal Dis Res 9: 194-199.

6. Al-Azzam SI, Al-Husein BA, Alzoubi F, Masadeh MM, Al-Horani MA (2007) Self medication with antibiotics in Jordanian population. Int $\mathrm{J}$ Occup Med Environ Health 20: 373-380.

7. Sihavong A, Lundborg CS, Syhakhang L, Akkhavong K, Tomson G, et al. (2006) Antimicrobial self medication for reproductive tract infections in two provinces in Lao People's Democratic Republic. Sex Transm Infect 82: 182-186.

8. Goossens H, Ferech M, Vander Stichele R, Elseviers M (2005) Outpatien antibiotic use in Europe and association with resistance: a cross-national database study. Lancet 365: 579-587.

9. Zaidi AK, Huskins WC, Thaver D, Bhutta ZA, Abbas Z, et al. (2005) Hospitalacquired neonatal infections in developing countries. Lancet 365: 1175-1188.

10. Lestari ES, Severin JA, Filius PM, Kuntaman K, Duerink DO, et al. (2008)
Antimicrobial resistance among commensal isolates of Escherichia col and Staphylococcus aureus in the Indonesian population inside and outside hospitals. Eur J Clin Microbiol Infect Dis 27: 45-51.

11. Farrell DJ, Jenkins SG, Brown SD, Patel M, Lavin BS, et al. (2005) Emergence and spread of streptococcus pneumoniae with erm $(B)$ and mef $(A)$ resistance. Emerg Infect Dis 11: 851-858.

12. Levy SB (2005) Antibiotic resistance-the problem intensifies. Adv Drug Deliv Rev 57: 1446-1450.

13. Hidayat B, Thabrany H, Dong H, Sauerborn R (2004) The effects of mandatory health insurance on equity in access to outpatient care in Indonesia. Health Policy Plan 19: 322-335

14. Widayati A, Suryawati S, de Crespigny C, Hiller JE (2011) Self medication with antibiotics in Yogyakarta City Indonesia: a cross sectional population-based survey. BMC Res Notes 4: 491.

15. Davies J, Davies D (2010) Origins and evolution of antibiotic resistance. Microbiol Mol Biol Rev 74: 417-433

16. Mainous AG 3rd, Everett CJ, Post RE, Diaz VA, Hueston WJ (2009) Availability of Antibiotics for Purchase Without a Prescription on the Internet. Ann Fam Med 7: 431-435.

17. Behrens RH, Awad AI, Taylor RB (2002) Substandard and counterfeit drugs in developing countries. Trop Doct 32: 1-2.

18. Issack MI (2001) Substandard drugs. Lancet 358: 1463.

19. Syhakhang L, Lundborg CS, Lindgren B, Tomson G (2004) The quality of drugs in private pharmacies in Lao PDR: a repeat study in 1997 and 1999. Pharm World Sci 26: 333-338

20. Prazuck T, Falconi I, Morineau G, Bricard-Pacaud V, Lecomte A, et al. (2002) Quality control of antibiotics before the implementation of an STD program in Northern Myanmar. Sex Transm Dis 29: 624-627.

21. Shakoor O, Taylor RB, Behrens RH (1997) Assessment of the incidence of substandard drugs in developing countries. Trop Med Int Health 2: 839-845.

22. Taylor RB, Shakoor O, Behrens RH, Everard M, Low AS, et al. (2001) Pharmacopoeial quality of drugs supplied by Nigerian pharmacies. Lancet 357 1933-1936.

23. World Health Organization (WHO): What encourages counterfeiting of medicines?

24. Grundmann $\mathrm{H}$, Klugman KP, Walsh $\mathrm{T}$, Ramon-Pardo $\mathrm{P}$, Sigauque $\mathrm{B}$, et al. (2011) A framework for global surveillance of antibiotic resistance. Drug Resist Updat 14: 79-87. 